\title{
Comparative Clinical and Histological Study of Narrow Band UVB Phototherapy Versus Combined Narrow Band UVB Phototherapy and Microneedling in Treatment of Vitiligo
}

\author{
AMIRA A.A. EL-ZEFTAWY, M.Sc.*; WAFAA M. RAMADAN, M.D.**; \\ KARIMA I. EL-DESOUKY, M.D.*** and NAEIM M. ABD EL-NABY, M.D.**
}

Dermatology \& Leprosy Hospital, Ministry of Health* and The Department of Dermatology \& Venereology** and Pathology***, Faculty of Medicine, Tanta University, Tanta, Egypt

\begin{abstract}
Background: Vitiligo is an acquired pigmentary disorder of unknown etiology that affects up to $1 \%$ of the general population of all skin types.

It is a multifactorial disorder. There are numerous medical and surgical treatments aimed at repigmentation.

Microneedling is a minimally invasive procedure that uses fine needles to puncture the epidermis. The indications for microneedling therapy have grown significantly and it is becoming a widely used treatment in Dermatology.

Aim of Study: To study the clinical and histological efficacy of combined NB-UVB phototherapy and microneedling versus NB-UVB phototherapy in the treatment of vitiligo.

Patients and Methods: Twenty patients were divided into two Groups (A \& B), each of 10 patients. Both groups were matched regarding age, sex, skin type and have a depigmented patch at the same corresponding site. Group A was subjected to microneedling with dermapen at one depigmented patch followed by NB-UVB phototherapy sessions twice weekly for three months. Group B was subjected to NB-UVB phototherapy sessions twice weekly for three months. Two Skin biopsies one before and one after the therapy were taken for immunohistochemical examination by HMB 45 .

Results: The mean percentage of improvement was significantly high in Group A $(48.50 \% \pm 26.46)$ than Group B (20.0\% \pm 19.58$)$. In Group A $20 \%$ showed mild improvement (G1), 20\% showed moderate improvement (G2), (40\%) showed good improvement (G3) and $20 \%$ showed excellent improvement (G4). In Group B 30\% showed no improvement, 50\% showed mild improvement (G1), 10\% showed moderate improvement (G2) and 10\% showed good improvement (G3). There was statistically significant difference between both groups $\left(p=0.027^{*}\right)$.
\end{abstract}

Immunohistochemical changes revealed marked expression of HMB45 in Group A more than Group B, the mean of color intensity in Group A was $0.05 \pm 0.04$ and a median of 0.03

Correspondence to: Dr. Amira A.A. El-Zeftawy, Dermatology \& Leprosy Hospital, Ministry of Health, Tanta, Egypt while in Group B was $0.01 \pm 0.01$. There was statistically significant difference between both groups $(p=0.002 *)$.

Conclusion: Microneedling prior to NB-UVB phototherapy sessions was clearly superior to NB-UVB phototherapy alone with accelerating response. Microneedling is a tolerable procedure, safe with minimal side effects.

Key Words: Microneedling - NB- UVB phototherapy - HMB45 - Vitiligo.

\section{Introduction}

VITILIGO is an acquired pigmentary disorder that is clinically characterized by the development of white macules related to the selective loss of melanocytes [1]. Vitiligo affects approximately $1 \%$ of the world population of all skin types [2].

It is a multifactorial disorder including genetic, auto-immune, neurogenic factors, intrinsic defect of melanocytes (self destructive theory), oxidative stress theory, reduced melanocyte survival theory, trans-epidermal melanocytorrhagy theory and convergence theory is also suggested [3-6].

It occurs equally in people of all skin colors and races, both males and females are equally affected [7]. The psychological impacts of vitiligo are completely evident, especially in female patients [8].

As it has a marked effect on the patients' general appearance, their quality of life may be influenced dramatically by the disease [9] .

There are several treatment modalities such as topical, systemic and surgical techniques. Corticosteroids, calcineurin inhibitors, Vitamin D analogues and photo therapy are some of the well 
known reported therapies, which have different response rates [10].

The excimer laser $(308 \mathrm{~nm})$ yields better results than conventional light therapy in the treatment of vitiligo [11].

Surgical procedures aim to replace the melanocytes with ones from a normally pigmented autologous donor site. Several melanocyte transplantation techniques can be performed [12] .

Narrow band ultraviolet B (NB-UVB, $311 \mathrm{~nm}$ ) is the selected type of phototherapy with $40-70 \%$ repigmentation rate depending on the affected site $[13,14]$.

NB-UVB is used routinely two to three times a week for about 30-60 sessions [13,14]. Repigmentation usually appears in a perifolicular pattern and/or from the periphery of the lesions [15] .

There are some reports of induction of repigmentation in the stable patches of vitiligo by combined phototherapy and needling from pigmented margins towards central areas with variable results [16-19].

Microneedling is a minimally invasive procedure that uses fine needles to puncture the epidermis. The indications for microneedling therapy have grown significantly, and it is becoming a widely used treatment in Dermatology [20].

There are few studies regarding using Microneedling as adjuvant therapy of vitiligo $[21,22]$. So it is worth to evaluate this new line of treatment.

\section{Aim of the work:}

The aim of the work was to compare clinical and histological efficacy of NB-UVB phototherapy with combined microneedling and NB-UVB phototherapy in treatment of vitiligo.

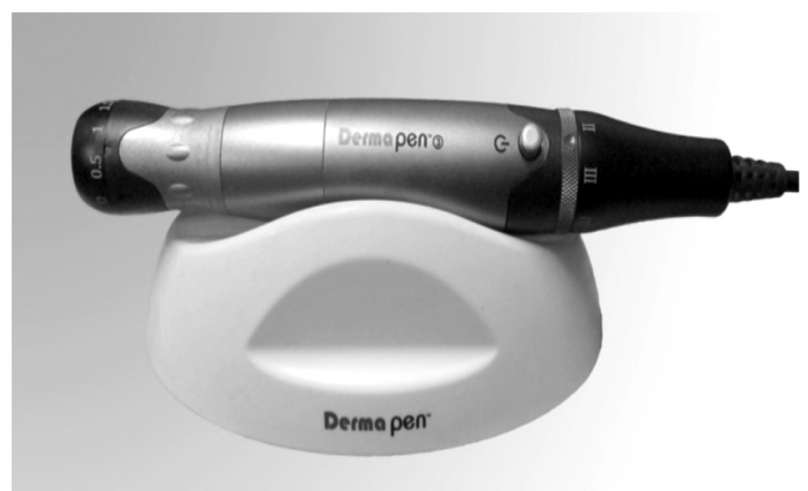

\section{Patients and Methods}

The study included 20 patients with vitiligo, selected from the outpatient clinic of Dermatology and Venereology Department in Tanta University Hospital from April 2016 to March 2017.

Divided into two Groups (A \& B), each group enrolled 10 patients. Both groups were matched regarding age, sex, skin type and have at least one depigmented patch at the same corresponding site.

\section{Inclusion criteria:}

- The age of patients was between $7 \& 65$ years.

- Patients with vitiligo patches who didn't receive any systemic treatment or phototherapy in the last 12 months.

- Patients who have no other dermatological diseases.

\section{Exclusion criteria:}

- Any contraindication to phototherapy.

- Patients with impaired blood clotting or anticoagulant users.

- Patients with cutaneous infection.

- Patients with liver diseases.

- Pregnancy and lactation.

- Group A: Was subjected to microneedling (with dermapen at one depigmented patch) followed by NB-UVBphototherapy sessions twice weekly for three months.

- Group B: Was subjected to NB-UVB phototherapy sessions twice weekly for three months.

Microneedling was done using Dermapen. Its model is Dermapen 3TM, Australia. Fig. (1).

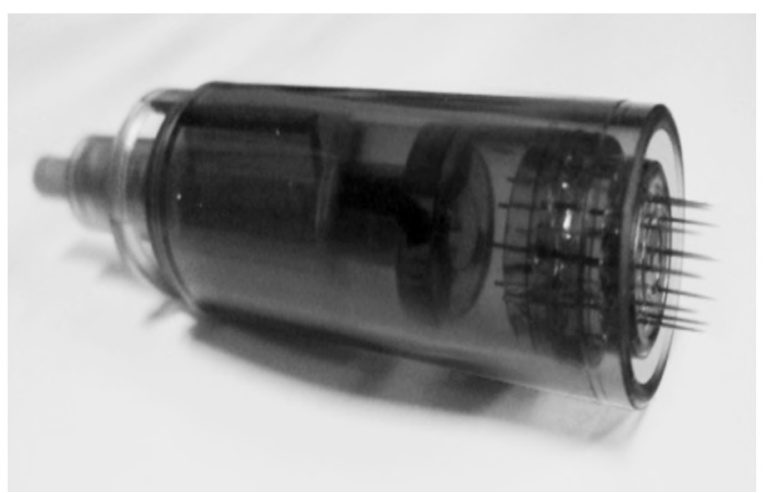

Fig. (1): Dermapen 3 and its disposable needle. 


\section{Technique of microneedling:}

- The skin was cleaned by ethyl alcohol and topical anaesthetic cream was applied under occlusion for 30 minutes.

- Sterilized needle was put into the top of the hand piece.

- The Dermapen was set at (needle depth 0.5 to $1 \mathrm{~mm}$ ) $0.5 \mathrm{~mm}$ for the patches of the buttocks, breast, and back of the neck \& $1 \mathrm{~mm}$ for the patches of the knee, elbow, and acral areas.

- Speed level ring was turned on the speed IV.

- The Dermapen then was applied peripendcular on the treated area moving vertically and horizontally from the peripheral pigmented border (and pigmented dots in the lesion if present) and slide toward the central depigmented area.

- The end point was the appearance of erythema in the treated area (Fig. 2).

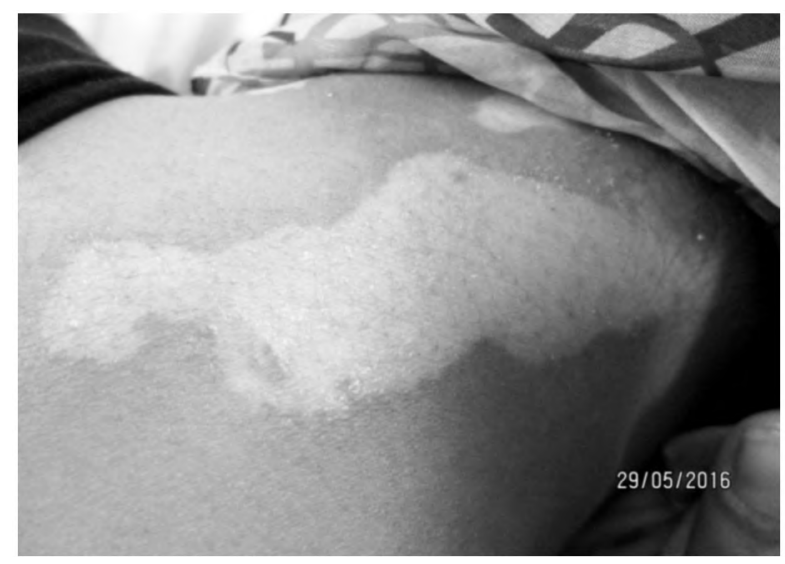

Fig. (2): Erythema after microneedling.

\section{Radiation source:}

Waldmann full body UV therapy system (UV $100 \mathrm{WL}$ ) with folding side parts, (Herbert Waldmann, Villingen-Schwenningen, Germany) has 8 Phillips TL-01 fluorescent lamps (Einhoven, Netherland) with a radiation spectrum of $310-315 \mathrm{~nm}$ with a peak of $311 \mathrm{~nm}$.

\section{Protocol of irradiation:}

Patients started at a dose of $0.30 \mathrm{~J} / \mathrm{cm}^{2}$. Dose was increased by $30 \%$ increments according to patient's response and tolerance. Dose was fixed when minimal erythema dose occurred.

\section{Evaluation of the treatment:}

\section{Clinical assessment:}

- Photographs were taken at baseline and before each session.
- The repigmentation responses were expressed qualitatively as:

- $(0)=$ No change $(\mathrm{G} 0)$

- $(0-25 \%)=$ Mild improvement (G1).

- $(26-50 \%)=$ Moderate improvement (G2).

- $(51-75 \%)=$ Good improvement (G3).

- $(76-100 \%)=$ Excellent improvement (G4).

\section{Immunohistological evaluation:}

Two skin biopsies one before and one after the therapy (3 months later) for:

- Immunohistochemistry by HMB45.

Morphometric study for color intensity of HMB45 immunoreactivity and statistical analysis: The software (Image J) (National Institute of Health, Bethesda, Mayland, USA) was used to measure the color intensity of HMB45 immunoreactivity in both Groups A and B [23]

\section{Statistical analysis:}

The collected data were organized, tabulated, and statistically analyzed using SPSS software (Statistical Package for the Social sciences, Version 20 SPSS Inc. Chicago, IL, USA). $p$-value is the probability. Chi-square test was used as a test of significance. Significance was considered when $p$-value was $<0.05$.

\section{Results}

Demographic and clinical data of the studied vitiligo patients:

- Regarding the age, sex of the patients:

As regards the age of total patients, it was ranged from 11-53 year with a mean of 29.70 \pm 12.58 years and a median of 29.50 . They were 8 males (40\%) and 12 females (60\%) Table (1).

\section{- Regarding the family history and Precipitating Factors:}

Positive family history was in 7 patients (35\%) and negative family history was in 13 patients $(65 \%)$. Vitiligo was precipitated by sun burn in 6 patients $(30 \%)$ and by stress in 10 patients $(50 \%)$ and by trauma in 4 patients (20\%) Table (2).

- Regarding the skin type of the patients, type of vitiligo and graying of hair in the lesions:

Eighteen patients $(90 \%)$ were of skin type III and 2 patients (10\%) were of skin type IV. 15 patients $(75 \%)$ having generalized vitiligo and 5 patients $(25 \%)$ having focal vitiligo. Graying of hair in the lesion was noticed in 4 patients (20\%) and was absent in 16 patients (80\%) Table (3). 


\section{- Regarding the site of the lesion:}

Four patients had lesions on the buttocks $(20 \%)$, 4 patients had lesions on the back of the neck $(20 \%), 4$ patients had lesions on breast $(20 \%), 2$ patients had lesions on elbows $(10 \%), 4$ patients had lesions on knees $(20 \%)$ and 2 patients had acral lesions (10\%) as seen in Table (4).

- Evaluation of the clinical efficacy of the therapeutic procedures:

Regarding the start of response between both groups:

In Group A; the start of response ranged from 3-10 weeks with a mean of $5.90 \pm 2.33$ weeks and a median of 5.50 while in Group B; the start of response ranged from 5-12 weeks with a mean of $9.10 \pm 2.73$ and a median of 9.50. There was statistically significant difference between both groups $\left(p=0.017^{*}\right)$ Table (5).

- Regarding the degree and percentage of improvement:

The degree of improvement: Group A; 2 patients (20\%) showed mild improvement (G1), 2 patients (20\%) showed moderate improvement (G2), 4 patients $(40 \%)$ showed good improvement (G3) and 2 patients $(20 \%)$ showed excellent improvement (G4). Group B; 3 patients (30\%) showed no

Group A
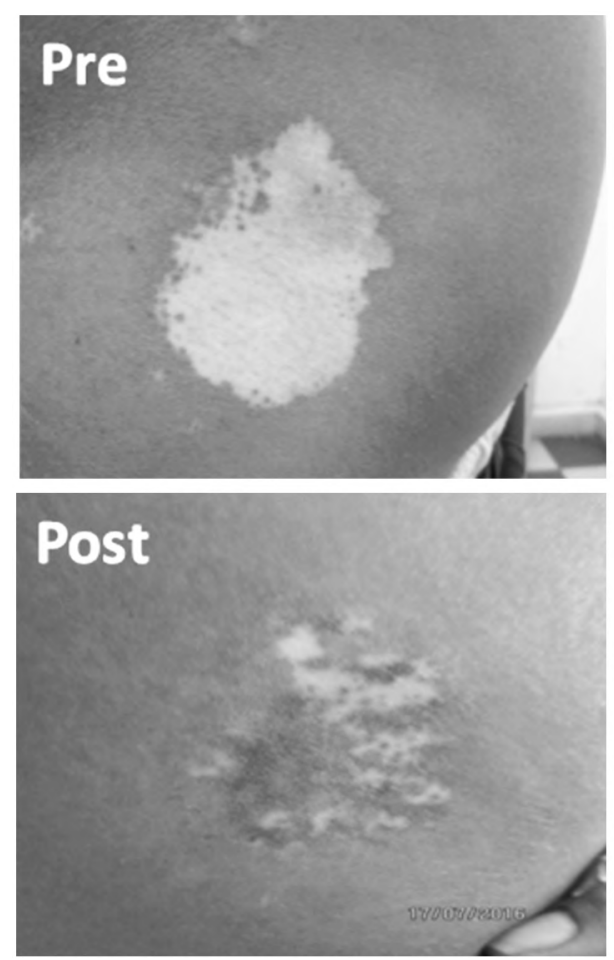

Excellent improvement improvement, 5 patients $(50 \%)$ showed mild improvement (G1), one patient (10\%) showed moderate improvement (G2) and one patient (10\%) showed good improvement (G3).

The percentage of improvement: Group A showed improvement ranged from $5 \%$ to $85 \%$ with a mean of $48.50 \% \pm 26.46$ and a median $55 \%$. Group B showed improvement ranged from 0\%-60\% with a mean $20.0 \% \pm 19.58$ and a median $20 \%$, there was statistically significant difference between both groups $\left(p=0.027^{*}\right)$ as seen in Table (6).

\section{- The immunohistochemical examination:}

Before treatment; immunohistochemical examination of sections stained by HMB 45 confirmed the absence of melanocytes, melanosomes in all patients of both groups.

After treatment; positivity for HMB45 confirmed the reappearance of melanocytes and melanosomes in all patients of both groups with variable degrees and when compairing both groups: Group A showed color intensity ranged from 0.010.12 with a mean of $0.05 \pm 0.04$ and a median of 0.03 while Group B showed color intensity ranged from $0.01-0.03$ with a mean $0.01 \pm 0.01$ and a median of 0.01 . There was statistically significant difference between both groups $(p=0.002 *)$ Table $(7)$.
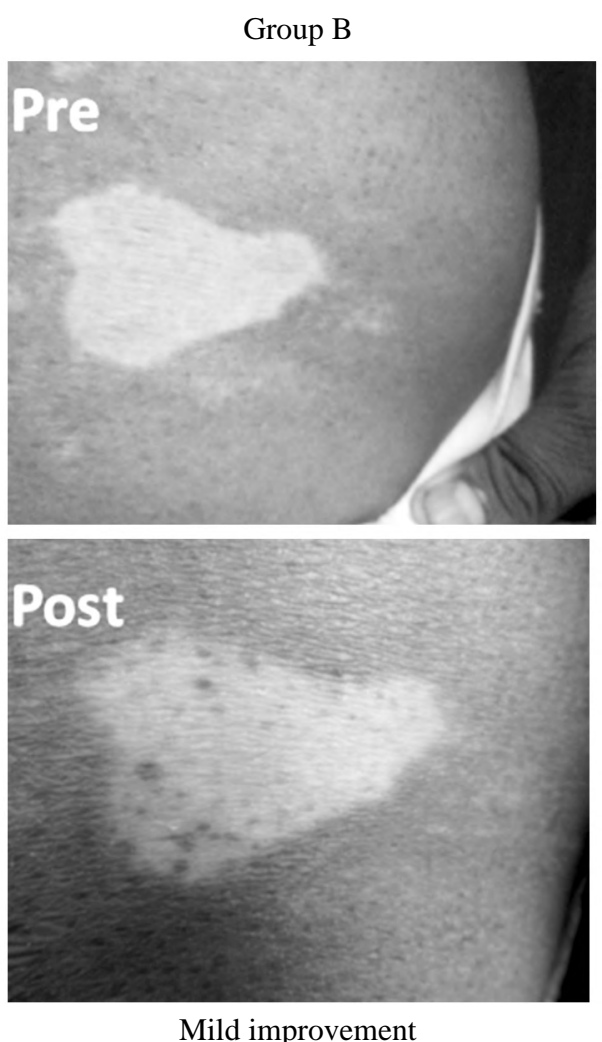

Fig. (3): Male patient 32 years old with vitiligo in buttocks treated with combined microneedling and phototherapy (Group A), showing excellent improvement, compared with male patient 34 years old with vitiligo in buttocks treated with phototherapy only (Group B), showing mild improvement. 
Group A
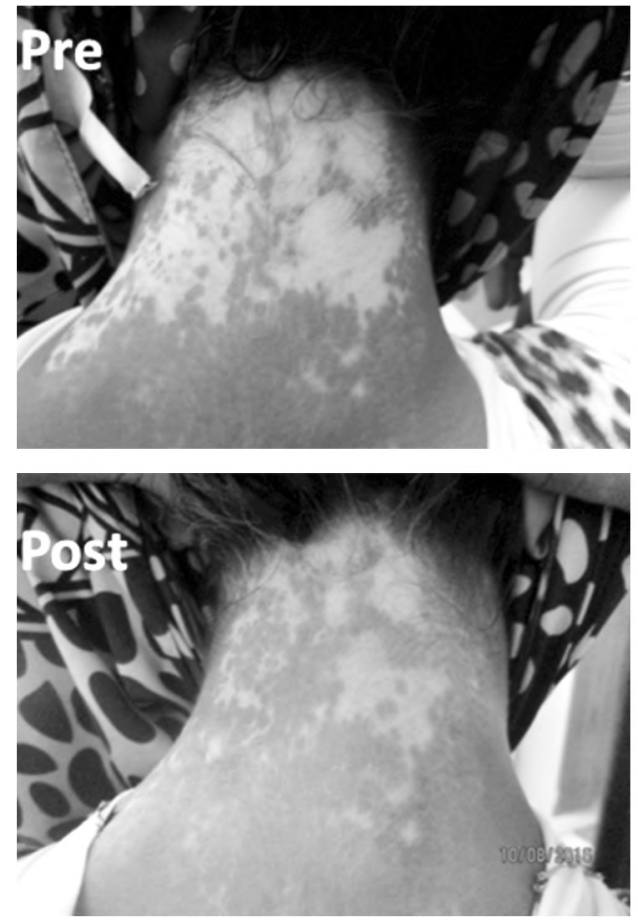

Excellent improvement
Group B
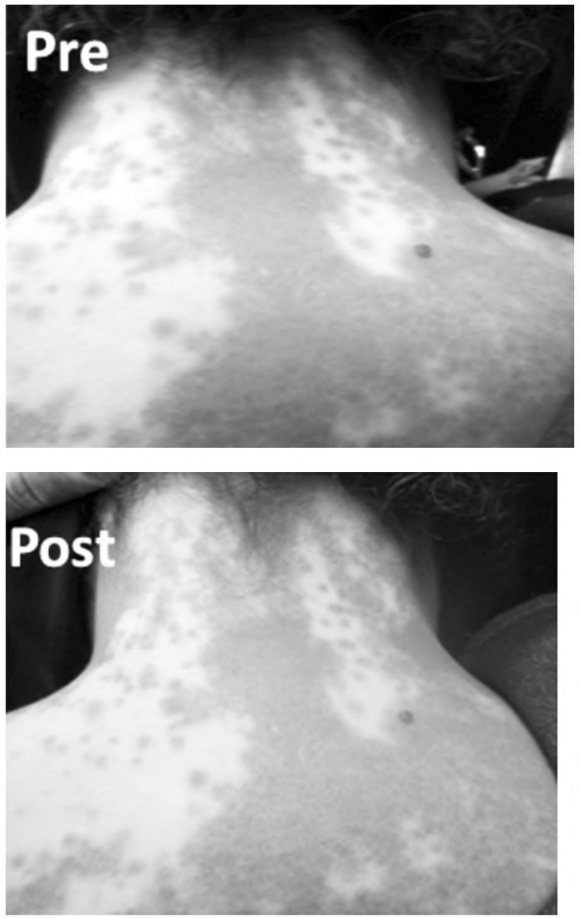

Mild improvement

Fig. (4): Female patient 17 years old with vitiligo in back of neck treated with combined microneedling and phototherapy (Group A), showing excellent improvement. Compared with female patient 19 years old with vitiligo in back of neck treated with phototherapy only (Group B), showing mild improvement.

Group A
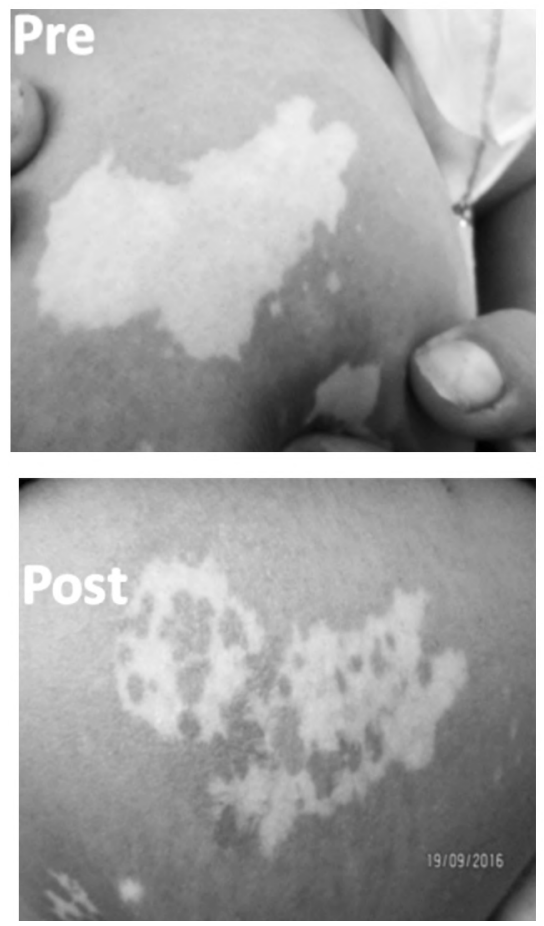

Good improvement
Group B
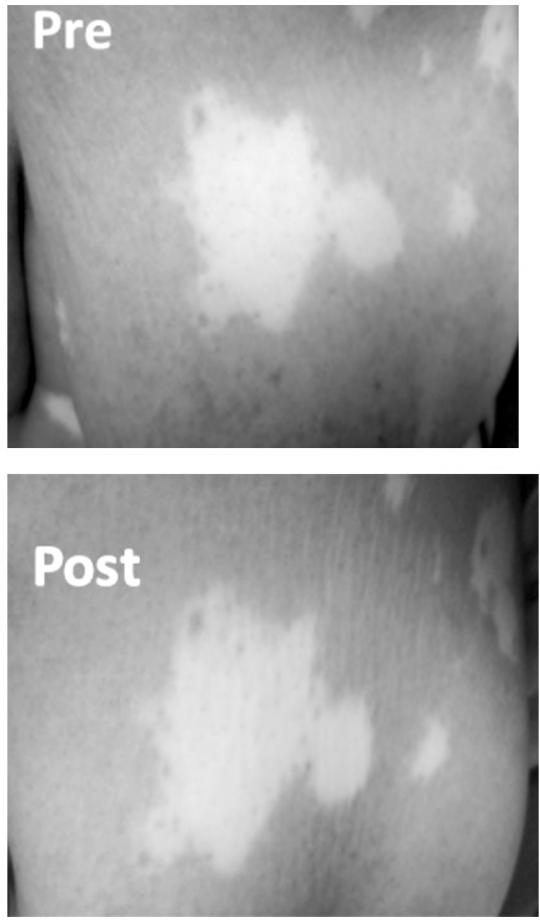

No improvement

Fig. (5): Female patient 21 years old with vitiligo in breast treated with combined microneedling and phototherapy (Group A), showing good improvement. Compared with female patient 25 years old with vitiligo in breast treated with phototherapy only (Group B), showing no improvement. 

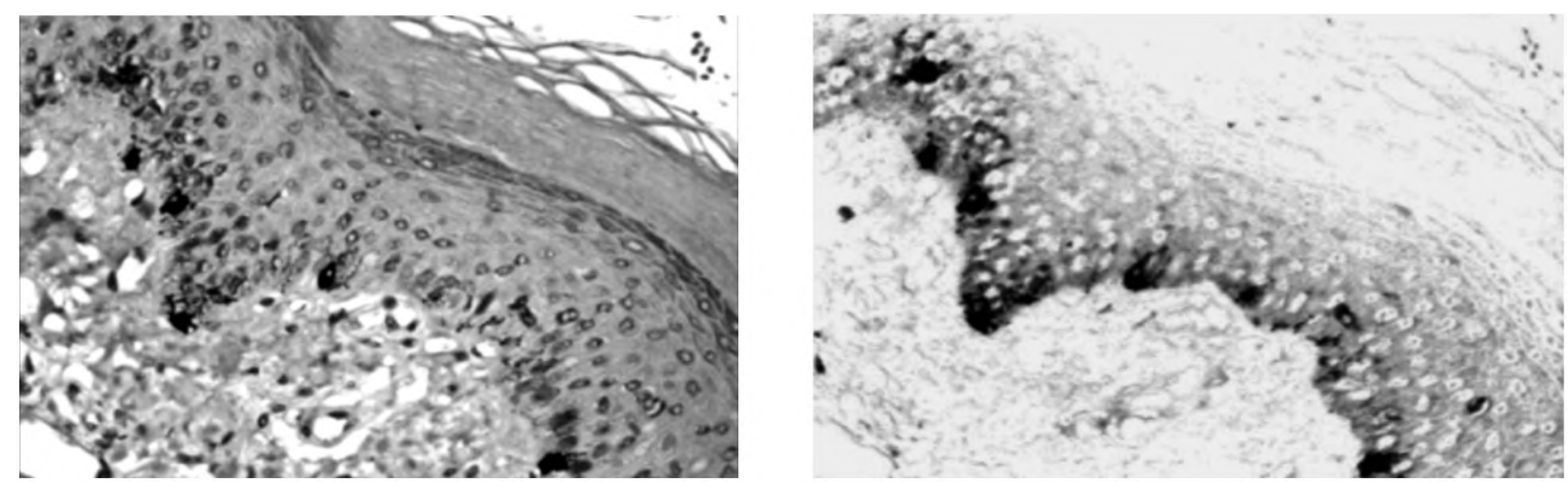

Fig. (6): Acase of vitiligo after treatment (Group A) showing color intensity 0.0364 of HMB45 in the basal keratinocytes [ABC X400] (A) HMB45 stained photo. (B) The same photo analyzed by J image program.
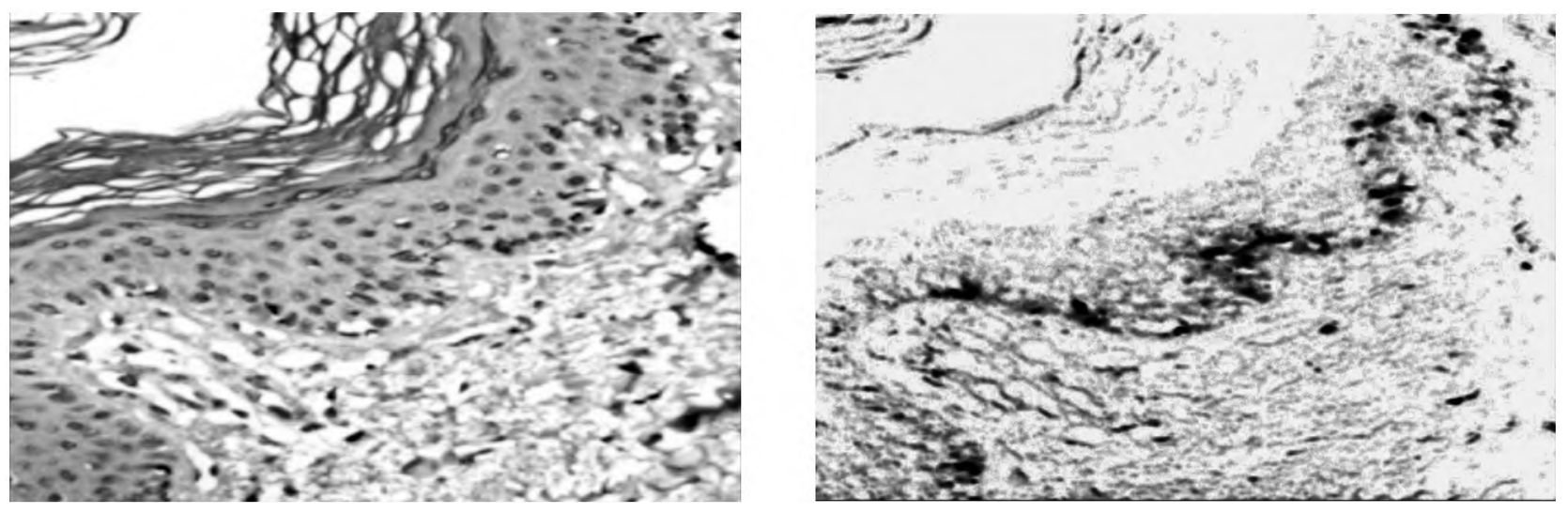

Fig. (7): Acase of vitiligo after treatment (Group B) showing color intensity 0.0266 of HMB45 in the basal keratinocytes [ABC X400] (A) HMB45 stained photo. (B) The same photo analyzed by J image program.

Table (1): Demographic data of the studied vitiligo patients $(n=20)$.

\begin{tabular}{|c|c|c|}
\hline & No & $\%$ \\
\hline \multicolumn{3}{|l|}{ Age (years): } \\
\hline Min.-max. & \multicolumn{2}{|c|}{$11.0-53.0$} \\
\hline Mean \pm SD. & \multicolumn{2}{|c|}{$29.70 \pm 12.58$} \\
\hline Median & \multicolumn{2}{|c|}{29.50} \\
\hline \multicolumn{3}{|l|}{ Sex: } \\
\hline Male & 8 & 40.0 \\
\hline Female & 12 & 60 \\
\hline
\end{tabular}

Table (2): Family history, precipitating factors of the studied vitiligo patients $(n=20)$.

\begin{tabular}{|c|c|c|c|c|c|}
\hline \multirow[b]{2}{*}{ Family history: } & \multirow[t]{2}{*}{ No. } & \multirow[t]{2}{*}{$\%$} & \multicolumn{3}{|c|}{$\begin{array}{l}\text { Table (4): Duration of disease and site of lesions in the studied } \\
\text { vitiligo patients }(n=20) \text {. }\end{array}$} \\
\hline & & & Site of lesions & No. & $\%$ \\
\hline Positive & 7 & 35.0 & Buttocks & 4 & 20.0 \\
\hline & & & Back of the neck & 4 & 20.0 \\
\hline Precipitating factors: & & & Breast & 4 & 20.0 \\
\hline Sun burn & 6 & 30.0 & Elbow & 2 & 10.0 \\
\hline Stress & 10 & 50.0 & Knee & 4 & 20.0 \\
\hline Trauma & 4 & 20.0 & Acral & 2 & 10.0 \\
\hline
\end{tabular}

Table (3): Skin types, type of vitiligo and graying of hair in the lesion in the studied vitiligo patients $(n=20)$.

$\begin{array}{lll}\text { Skin type: } & & \\ \text { III } & 18 & 90 \\ \text { IV } & 2 & 10 \\ \text { Type of vitiligo: } & & \\ \text { Generalized } & 15 & 75.0 \\ \text { Focal } & 5 & 25.0\end{array}$

Graying of hair in the lesions:

$\begin{array}{lll}\text { Negative } & 16 & 80.0 \\ \text { Positive } & 4 & 20.0\end{array}$


Table (5): Comparison between the two studied vitiligo groups according to start of response (weeks).

\begin{tabular}{lllll}
\hline $\begin{array}{l}\text { Start of response } \\
\text { (weeks) }\end{array}$ & $\begin{array}{c}\text { Group A } \\
(\mathrm{n}=10)\end{array}$ & $\begin{array}{c}\text { Group B } \\
(\mathrm{n}=10)\end{array}$ & $\mathrm{U}$ & $p$ \\
\hline Min.-max. & $3.0-10.0$ & $5.0-12.0$ & $18.50^{*}$ & $0.017^{*}$ \\
Mean \pm SD. & $5.90 \pm 2.33$ & $9.10 \pm 2.73$ & & \\
Median & 5.50 & 9.50 & & \\
\hline
\end{tabular}

Table (6): Comparison between the two studied vitiligo groups according to degree and percentage of improvement.

\begin{tabular}{llllllc}
\hline \multirow{2}{*}{$\begin{array}{l}\text { Degree of } \\
\text { improvement }\end{array}$} & \multicolumn{2}{c}{$\begin{array}{c}\text { Group A } \\
(\mathrm{n}=10)\end{array}$} & \multicolumn{2}{c}{$\begin{array}{c}\text { Group B } \\
(\mathrm{n}=10)\end{array}$} & $\begin{array}{c}\text { Test } \\
\text { of sig. }\end{array}$ & $p$ \\
\cline { 2 - 5 } & No. & $\%$ & No. & $\%$ & & \\
\hline G0 & 0 & 0.0 & 3 & 30.0 & $\chi^{2}=$ & $\mathrm{MC}_{p=}$ \\
G1 & 2 & 20.0 & 5 & 50.0 & 7.492 & 0.100 \\
G2 & 2 & 20.0 & 1 & 10.0 & & \\
G3 & 4 & 40.0 & 1 & 10.0 & & \\
G4 & 2 & 20.0 & 0 & 0.0 & & \\
Min.-max. & $5.0-85.0$ & $0.0-60.0$ & $\mathrm{U}=$ & $0.027^{*}$ \\
Mean \pm SD. & $48.50 \pm 26.46$ & $20.0 \pm 19.58$ & $21.0^{*}$ & \\
Median & 55.0 & & 20.0 & & & \\
\hline
\end{tabular}

Table (7): Comparison between the two studied vitiligo groups according to immunohistochemical evaluation (optical density).

\begin{tabular}{lllll}
\hline $\begin{array}{l}\text { Immunohistochemical } \\
\text { evaluation } \\
\text { (color intensity) }\end{array}$ & $\begin{array}{c}\text { Group A } \\
(\mathrm{n}=10)\end{array}$ & $\begin{array}{c}\text { Group B } \\
(\mathrm{n}=10)\end{array}$ & $\mathbf{U}$ & $p$ \\
\hline Min.-max. & $0.01-0.12$ & $0.01-0.03$ & $9.0^{*}$ & $0.002^{*}$ \\
Mean \pm SD. & $0.05 \pm 0.04$ & $0.01 \pm 0.01$ & & \\
Median & 0.03 & 0.01 & & \\
\hline
\end{tabular}

\section{Discussion}

Vitiligo is an acquired pigmentary disorder that is clinically characterized by the development of white macules related to the selective loss of melanocytes [1].

Vitiligo affects approximately $1 \%$ of the world population of all skin types [2]. It is a multifactorial disorder. The psychological impacts of vitiligo are completely evident [17].

A large variety of therapeutic agents are being tried for the treatment of vitiligo [24]. NB-UVB is considered to be the most effective and safe initial treatment of choice for the treatment of moderate to severe vitiligo [25]. However, the response to NB-UVB may be slowed and delayed [26].

Wounding the lesion to stimulate the melanocytes from the periphery and the black hair follicles to proliferate, migrate and repigment the lesion was tried using therapeutic dermabrasion [27], cryosurgery [28], local application of phenol or trichloroacetic acid [29], laser ablation [30], needling $[16,17]$ and latest but not last is microneedling [21,22]

The present study included 20 patients with vitiligo. The selected patients were divided into two Groups (A \& B), each group enrolled 10 patients. Both groups were matched in age, sex, skin type and having at least one depigmented patch at the same corresponding site.

Group A was subjected to microneedling with dermapen at one depigmented patch followed by NB-UVB phototherapy sessions twice weekly for three months. Group B was subjected to NB-UVB phototherapy sessions twice weekly for three months.

In the present study the age of total vitiligo patients ranged from 11-53 years with a mean of $29.70 \pm 12.58$ years, the mean of age of onset was 21.6 years, $40 \%$ males and $60 \%$ females (Table 1), $35 \%$ of the patients had positive family history (Table 2), graying of hair in the lesions was noticed in $20 \%$ (Table 3). The difference of the percentages between our study and the others $[17,21,22]$ regarding to the age, sex, family history and graying of hair in the lesions may be attributed to different number, races and genetics of the patients, also different environmental factors, and may be due to the fact that vitiligo varies considerably among different geographical regions and ethnic groups [31].

Regarding the precipitating factors in the present study, skin trauma, sunburn and psychological stress were found in $20 \%, 30 \%$ and $50 \%$ respectively of the patients (Table 2). It was reported that $10-76 \%$ of patients with generalized vitiligo gave a history of skin injury, emotional stress, sunburn and hormonal changes [17]. Among the precipitating factors in the present study the psychological stress was the most frequent triggering factor $(50 \%)$ which goes well with Manolache and Benea results [32]

In the present study graying of hair in the lesions was noticed in 4 patients (20\%). Which agreed with the study of Stanimirovic et al., [21] which reported that graying of hair in the lesions was noticed in 3 patients $(12 \%)$.

Regarding the type of vitiligo 15 patients (75\%) having generalized vitiligo and 5 patients $(25 \%)$ having focal vitiligo Fig. (8). This was in accordance with many reports which stated that Generalized vitiligo is the most common clinical presentation $[1,21,33]$ 
Concerning the start of response; there was statistically significant difference between both groups $\left(p=0.017^{*}\right)$ (Table 5). The repigmentation started earlier in Group A than Group B. This agrees with the results of Mohaghegh [17] that reported earlier repigmentation in side $B$ which was treated by combined needling and N-B UVB phototherapy than side A which was treated with N-B UVB phototherapy only. However, the results of Stanimirovic et al., [21] showed that the start of the repigmentation was the same on both sides and addition of microneedling did not improve the efficiency.

Regarding the degree of improvement in our study: In Group A; $20 \%$ of the patients showed mild improvement (G1), 20\% showed moderate improvement (G2), 40\% showed good improvement (G3) and 20\% showed excellent improvement (G4). In Group B; $30 \%$ of the patients showed no improvement (G0), 50\% showed mild improvement (G1), 10\% showed moderate improvement (G2) and $10 \%$ showed good improvement (G3). Generaly improvement occurred in 100\% of cases in Group A and $70 \%$ in Group B and marked improvement occurred in $60 \%$ of cases in Group A and $10 \%$ in Group B. Group A was statistically significant better than Group B ( $\left.p=0.027^{*}\right)$ (Table 6). These results were in accordance with many studies about the role of needling in vitiligo $[16,17,19]$.

Ahmad et al., [16] treated twenty three patients with 84 treated patches by needling, three times every week after incremental exposure to NBUVB, and each patient was treated for at least six months in a non-controlled study. Improvement occurred in $96.4 \%$ and marked improvement occurred in $94 \%$. They performed the horizontal needling after the NB-UVB sessions.

Study from Iran assessed the efficacy of narrowband UVB therapy with and without needling. The patches included in the study were divided into A and B groups. Both groups received NBUVB phototherapy (three/week) for three months. In addition, the $\mathrm{B}$ side also received needling by insulin syringe. Side B had statistically greater improvement $(p<0.05)$ in which improvement occurred in $83 \%$ and marked improvement occurred in $41.5 \%$ [17].

In this context, a recent study was conducted in Pakistan where 100 patients with vitiliginous patches were treated with needling with insulin syringe then were given narrowband UVB session three/week for at least six months. At follow-up, 91\% of patches had marked improvement [19]
The difference of the percentages in the current study than others may be attributed to different number, site of the lesions and duration of treatment.

Ebadi et al., [18] used needling (once/week) and UVB (3/week) and found that repigmentation was low (about $15.57 \%$ ); and, suggested that needling is not recommended. The poor response of the study of Ebadi et al., 2013 could be due to the few number of the needling sessions (once/week).

Regarding the immunohistochemical examination; when comparing both groups: Group A showed color intensity ranged from $0.01-0.12$ with a mean of $0.05 \pm 0.04$ and Group B showed color intensity ranged from $0.01-0.03$ with a mean 0.01 \pm 0.01 , there was statistically significant difference between both groups $\left(p=0.002^{*}\right.$ ) (Table 8$)$. To the best of our knowledge this score in evaluating the degree of melanization of skin specimens wasn't used in any previous study.

Ahmad et al., reported that repigmentation of white patches with needling occurs mainly from melanocytes which are physically dragged or pushed by the tip of the needle from the coloured margins of the patch or islands of pigment present within the patch [16]. Fabbrocini Get al., reported that microneedling relies on the principle of formation of microchannels with resultant healing response. These microchannels create a confluent zone of superficial bleeding that acts as a powerful stimulus for the release of various growth factors such as Platelet derived Growth Factor (PGF), Transforming Growth Factor Alpha and Beta (TGF$\alpha$ and TGF- $\beta$ ), and Fibroblast Growth Factor (FGF), which initiate the normal process of wound healing by stimulating the migration and proliferation of fibroblasts that promote collagen deposition [34].

\section{Conclusion:}

Microneedling prior to NB-UVB phototherapy sessions was clearly superior to NB-UVB phototherapy alone in the treatment of localized vitiligo lesions resistant to treatment.

The response to combined microneedling and NB-UVB phototherapy started earlier than the response to NB-UVB phototherapy alone.

Combined microneedling and NB-UVB phototherapy showed marked expression of HMB45 than NB-UVB phototherapy alone.

Microneedling prior to NB-UVB phototherapy sessionsis a tolerable procedure, effective, safe, with minimal side effects. 


\section{References}

1- ALIKHAN A., FELSTEN L.M., DALY M., et al.: Vitiligo: A comprehensive overview Part I. Journal of the American Academy of Dermatology, 65 (3): 473-91, 2011.

2- EZZEDINE K., ELEFTHERIADOU V., WHITTON M., et al.: Vitiligo. Lancet, 386: 74-84, 2015.

3- BASSIOUNY D.A. and SHAKER O.: Role of interleukin17 in the pathogenesis of vitiligo. Clinical and Experimental Dermatology, 36 (3): 292-7, 2011.

4- SCHALLREUTER K.U., MOORE J., WOOD J.M., et al.: Epidermal $\mathrm{H} 2 \mathrm{O} 2$ accumulation alters tetrahydrobiopterin (6BH4) recycling in vitiligo. Journal of Investigative Dermatology., 116 (1): 167-74, 2001.

5- LEE A.Y., KIM N.H., CHOI W.I., et al.: Less keratinocytederived factors related to more keratinocyte apoptosis in depigmented than normally pigmented suction-blistered epidermis may cause passive melanocyte death in vitiligo. Journal of Investigative Dermatology, 124 (5): 976-83, 2005.

6- VAN DEN WIJNGAARD R., WANKOWICZ-KALINSKA A., LE POOLE C., et al.: Local immune response in skin of generalized vitiligo patients. Journal of Technical Methods and Pathology, 80 (8): 1299-309, 2000.

7- GAWKRODGER D.J., ORMEROD A.D., SHAW L., et al.: Guideline for the diagnosis and management of vitiligo. British Journal of Dermatology, 159 (5): 1051-76, 2008.

8- ONGENAE K., VAN GEEL N., De SCHEPPER S., et al. Effect of vitiligo on self-reported health-related quality of life. British Journal of Dermatology, 152 (6): 1165-72, 2005.

9- DOLATSHAHI M., GHAZI P., FEIZY V., et al.: Life quality assessment among patients with vitiligo. Indian Journal of Dermatology, Venereology, and Leprology, 74 (6): 700-00, 2008.

10- FARIA A.R., TARLE R.G., DELLATORRE G., et al.: Vitiligo-Part 2-classification, histopathology and treatment. Anais Brasileiros de Dermatologia, 89 (5): 784-90, 2014.

11- BAYOUMI W., FONTAS E., SILARD L., et al.: Effect of a preceding laser dermabrasion on the outcome of combined therapy with narrowband ultraviolet B and potent topical steroids for treating nonsegmental vitiligo in resistant localizations. British Journal of Dermatology, 166: 208-11, 2012.

12- LEE D.Y., and CHOI S.C.: A proposal for the treatment guideline in segmental vitiligo. International Journal of Dermatology, 51 (10): 1274-5, 2012.

13- YONES S.S., PALMER R.A., GARIBALDINOS T.M., et al.: Randomized double-blind trial of treatment of vitiligo: Efficacy of psoralen-UV-A therapy vs. Narrowband-UV-B therapy. Archives of dermatology, 143 (5): 578-84, 2007.

14- HARTMANN A., LURZ C., HAMM H., et al.: Narrowband UVB311 nm vs. broad-band UVB therapy in combination with topical calcipotriol vs. placebo in vitiligo. International Journal of Dermatology, 44 (9): 736-42, 2005.

15- PASSERON J.-POAT.: Vitiligo and Other Disorders of Hypopigmentation. In: Jeffrey P. Callen L.C., Warren R.
Heymann,George J. Hruza, ed. Dermatology. Third ed: Elsevier Saunders, 1023-48, 2012.

16- AHMAD T.J., RASHID T., and RANI Z.: Needling: An adjunct to narrowband ultraviolet $B$ therapy in localized fixed vitiligo. Journal of Pakistan Association of Dermatologists, 18: 149-53, 2008.

17- MOHAGHEGH F., ASILIAN A., FAGHIHI G., et al.: A comparison between the efficacy of narrow band ultra violet $B$ phototherapy with and without needling of the lesion in the treatment of vitiligo. Journal of Research in Medical Sciences, 17: 131-33, 2012.

18- EBADI A., MORAVVEJ H., HEJAZI S., et al.: Efficacy and tolerability of needling as an adjuvant to narrowband ultraviolet B therapy in the treatment of vitiligo: A clinical trial. Iranian Journal of Dermatology, 16: 89-93, 2013.

19- BATOOL S., MALIK L. and JAHANGIR M.: Efficacy of narrowband ultraviolet B phototherapy with needling in patients of vitiligo. Journal of Pakistan Association of Dermatology, 25 (3): 177-82, 2015.

20- HOU A., COHEN B., HAIMOVIC A., et al.: Microneedling: A Comprehensive Review. Dermatologic surgery: Official publication for American Society for Dermatologic Surgery, 43 (3): 321-39, 2017.

21- STANIMIROVIC A., KOVACEVIC M., KOROBKO I., et al.: Combined therapy for resistant vitiligo lesions: NB-UVB, microneedling, and topical latanoprost, showed no enhanced efficacy compared to topical latanoprost and NB-UVB. Journal of Dermatologic Therapy, 29 (5): 31216, 2016.

22- KOROBKO I.V. and LOMONOSOV K.M.: A pilot comparative study of topical latanoprost and tacrolimus in combination with narrow-band ultraviolet B phototherapy and microneedling for the treatment of nonsegmental vitiligo. Journal of Dermatologic Therapy, 29 (6): $437-$ 41, 2016.

23- ImageJ [program]. Java 1.6.0-20 (64-bit) version: National Institute of Health, 2012.

24- FALABELLA R. and BARONA M.I.: Update on skin repigmentation therapies in vitiligo. Pigment Cell \& Melanoma Research, 22 (1): 42-65, 2009.

25- PARSAD D., KANWAR A.J. and KUMAR B.: Psoralenultraviolet A vs. narrow-band ultraviolet B phototherapy for the treatment of vitiligo. Journal of the European Academy of Dermatology and Venereology: JEADV, 20 (2): 175-7, 2006.

26- TAIEB A., ALOMAR A., BOHM M., et al.: Guidelines for the management of vitiligo: The european dermatology forum consensus. British Journal of Dermatology, 168 (1): 5-19, 2013.

27- SAVANT S.S.: Therapeutic spot and regional dermabrasion in stable vitiligo. Indian journal of dermatology, venereology and leprology, 62 (3): 139-45, 1996.

28- SAVANT S.S.: Cryosurgery with liquid nitrogen in stable vitiligo. Indian Journal of Dermatology, Venereology and Leprology, 65 (5): 246-7, 1999.

29- SAVANT S.S. and SHENOY S.: Chemical peeling with phenol: For the treatment of stable vitiligo and alopecia areata. Indian Journal of Dermatology, Venereology and Leprology, 65 (2): 93-8, 1999. 
30- SAVANT S.S.: Surgical therapy ofvitiligo: Current status. Indian Journal of Dermatology, Venereology and Leprology, 71 (5): 307-10, 2005.

31- SITEK J.C.: Vitiligo-loss of cutaneous pigmentation. Tidsskrift for Den Norske Laegeforening, 126 (18): 23702, 2006.

32- MANOLACHE L. and BENEA V.: Stress in patients with alopecia areata and vitiligo. Journal of the European Academy of Dermatology and Venereology: JEADV, (7) 21: 921-8, 2007.
33- YANG Y.S., CHO H.R., RYOU J.H., et al.: Clinical study of repigmentation patterns with either narrow-band ultraviolet B (NBUVB) or $308 \mathrm{~nm}$ excimer laser treatment in Korean vitiligo patients. International Journal of Dermatology, 49 (3): 317-23, 2010.

34- FABBROCINI G., FARDELLA N., MONFRECOLA A., et al.: Acne scarring treatment using skin needling. Clinical and experimental dermatology 34 (8): 874-9, 2009: 8749, 2009. tment Using Skin Needling. Clinical And Experimental Dermatology 34 (8): 874-9, 2009.

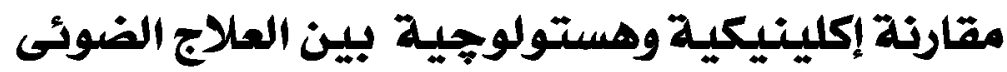

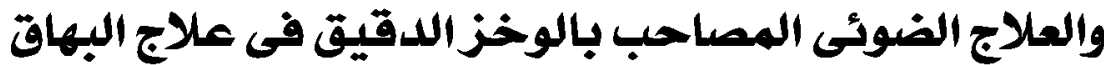

$$
\text { المقدمة: يعد البهاق أضطراب تصبغى شائع حيث يؤثر على 1٪ من سكان العالم. }
$$

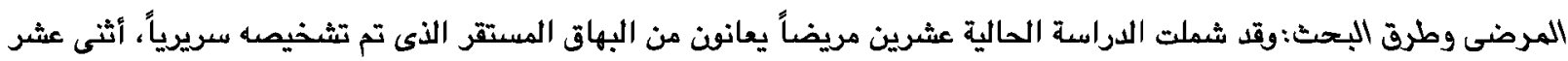

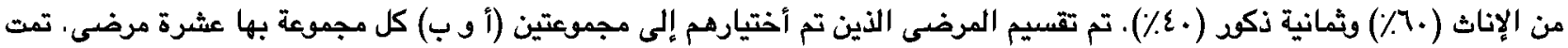
مطابقة كلتا المجموعتين فيما يتطلق بالعمر والجنس ونوع البشرة ولديهم منطقة مصابة بالبهاق على الألى الأقل فى نفس الموقع المقابل.

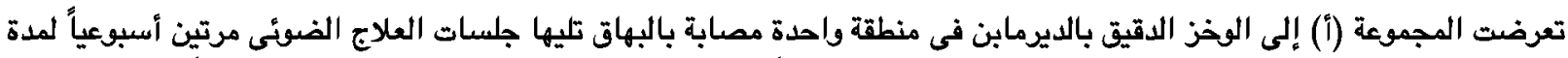

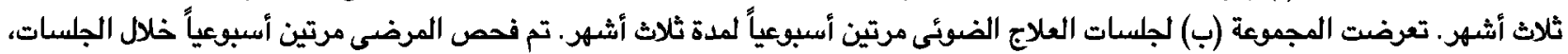
وتم أخذ الصورة فى بداية العلاج وقبل كل جلسة.

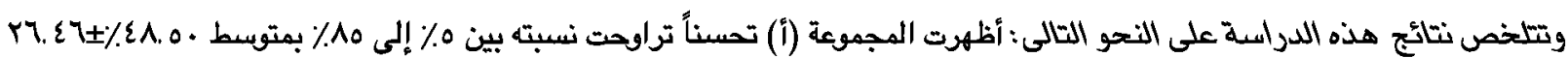

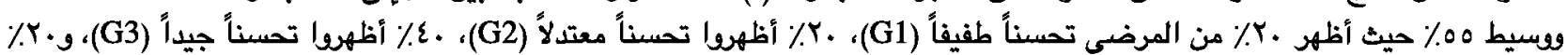

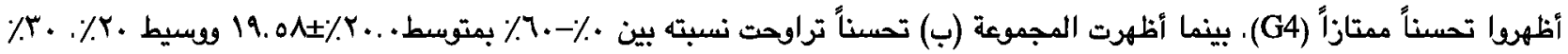

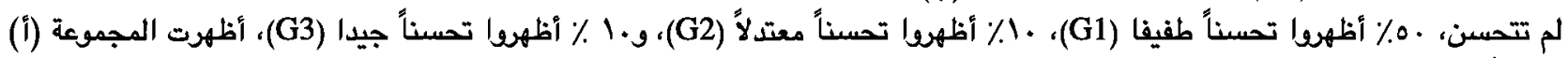

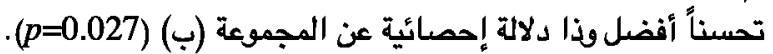

بداية إعادة التصبغ كان فى وقت سابق فى المجموعة (أ) بمتوسط (2.33 (5.90د) أسبوعاً عن المجموعة ب بمتوسط (2.7) كثفت التغيرات المناعية عن تعبير ملحوظ لصبغة HMB45 فى المجموعة (أ) أكثر من المجموعة (ب). المجموعة (أ) كثافة اللون تراوحت

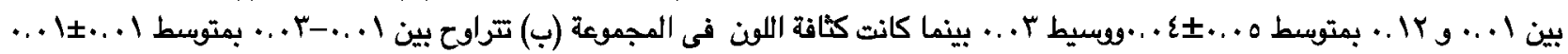

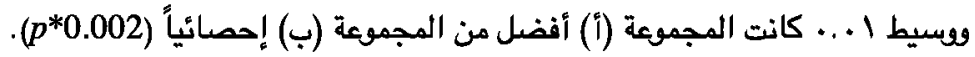

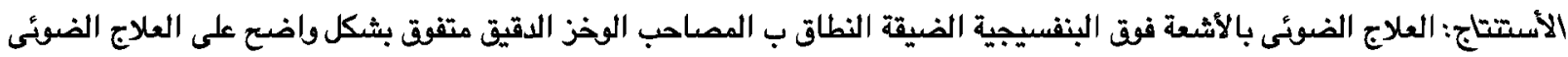

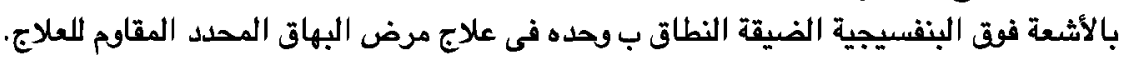

